\title{
Oxidative Stress-Induced Premature Senescence in Wharton's Jelly-Derived Mesenchymal Stem Cells
}

\author{
Kong Bung Choo ${ }^{1,2}{ }^{\bowtie}$, Lihui Tai ${ }^{1}$, K.Shri Hymavathee ${ }^{1}$, Chee Yin Wong ${ }^{3}$, Phan Nguyen Nhi \\ Nguyen ${ }^{1}$,Chiu-Jung Huang4, Soon Keng Cheong1,5 and Tunku Kamarul6 \\ 1. Centre for Stem Cell Research, Universiti Tunku Abdul Rahman, Selangor, Malaysia; \\ 2. Department of Preclinical Sciences, Faculty of Medicine and Health Sciences, Universiti Tunku Abdul Rahman, Selangor, Malaysia; \\ 3. Cytopeutics Sdn Bhd, Selangor, Malaysia; \\ 4. Department of Animal Science \& Graduate Institute of Biotechnology, Chinese Culture University, Taipei, Taiwan; \\ 5. Dean's Office, Faculty of Medicine and Health Sciences, Universiti Tunku Abdul Rahman, Selangor, Malaysia; \\ 6. Tissue Engineering Group, National Orthopaedic Centre of Excellence for Research and Learning, Department of Orthopaedic Surgery, \\ Faculty of Medicine, University of Malaya, 50603 Kuala Lumpur, Malaysia.
}

$\triangle$ Corresponding author: Kong Bung Choo, PhD. Professor, Faculty of Medicine and Health Sciences, Universiti Tunku Abdul Rahman, Sungai Long campus, Bandar Sungai Long, Cheras, 43000 Kajang, Selangor Darul Ehsan, Malaysia. E-mail: chookb@utar.edu.my Fax: (603) 90197026 Phone: (6012) 6873063

(ㅇ Ivyspring International Publisher. This is an open-access article distributed under the terms of the Creative Commons License (http://creativecommons.org/ licenses/by-nc-nd/3.0/). Reproduction is permitted for personal, noncommercial use, provided that the article is in whole, unmodified, and properly cited.

Received: 2013.12.13; Accepted: 2014.07.17; Published: 2014.09.13

\begin{abstract}
Background: On in vitro expansion for therapeutic purposes, the regenerative potentials of mesenchymal stem cells (MSCs) decline and rapidly enter pre-mature senescence probably involving oxidative stress. To develop strategies to prevent or slow down the decline of regenerative potentials in MSC culture, it is important to first address damages caused by oxidative stress-induced premature senescence (OSIPS). However, most existing OSIPS study models involve either long-term culture to achieve growth arrest or immediate growth arrest post oxidative agent treatment and are unsuitable for post-induction studies. Methods: In this work, we aimed to establish an OSIPS model of MSCs derived from Wharton's Jelly by hydrogen peroxide $\left(\mathrm{H}_{2} \mathrm{O}_{2}\right)$ treatment. Results: The optimal $\mathrm{H}_{2} \mathrm{O}_{2}$ concentration was determined to be $200 \mu \mathrm{M}$ to achieve OSIPS when MSC reached growth arrest in 3 to 4 passages post- $\mathrm{H}_{2} \mathrm{O}_{2}$ treatment. $\mathrm{H}_{2} \mathrm{O}_{2}$-treated cells became heterogeneous in morphology, and were irregularly enlarged and flattened with granular cytoplasm. The cells were stained positive for SA- $\beta$-galactosidase, a senescence marker, and were shown to express elevated levels of other well-characterized senescence molecular markers, including $\mathrm{p} 53, \mathrm{p} 2 \mathrm{I}, \mathrm{p} / 6$ and lysosomal $\beta$-galactosidase (GLBI) in real-time RT-PCR analysis. The OSIPS-like features were confirmed with three independent WJ-MSC lines. Conclusion: The establishment of an OSIPS model of WJ-MSC is a first step for subsequent investigation on molecular mechanisms of senescence and for screening potential anti-oxidative agents to delay or revert stressed-induced senescence.
\end{abstract}

Key words: mesenchymal stem cell, senescence, oxidative stress, hydrogen peroxide.

\section{Introduction}

Clinical advantages in autogenic transplantation of adult mesenchymal stem cells (MSC) have led to increased efforts in MSC research in recent years. MSC is able to differentiate into mesoderm- and non-mesoderm-derived tissues, and is readily obtained from numerous sources of the human adult body, including adult bone marrow and adipose tissues $[1,2]$. For cell-based therapies, MSCs isolated from donors are expanded in culture prior to validation and transplantation. However, as MSC ages on in vitro culture, MSC shows reduction in self-renewal ability and differentiation potentials [3,4], directly 
affecting characteristics of MSC and, hence, curative effects in clinical applications.

Senescence is a continuous process initiated from the first cell passage; with each self-renewal step to double the cell number, cells gradually grow older and lose their proliferative potentials due to irreversible growth arrest [5]. Senescent cells exhibit distinctive morphological changes, including flattened appearance, higher granularity, enlargement in size and changes in the ratio of nucleus to cytoplasm [6]. The pattern of gene expression inevitably changes but senescent cells remain metabolically active [7].

Replicative senescence of MSC from elderly donors or MSC in extended culture is characterized by increased expression of a set of senescence markers $[8,9]$. Cheng et al. demonstrated that senescence related-genes, such as p16, p21 and p53, are upregulated in long-term culture of bone marrow-MSC [10]. Senescence could be trigged by p53 and downstream p53-dependent genes to induce cell cycle arrest [11]. Besides p53, previous studies have linked over-expression of p16 to permanence of senescent state $[12,13]$. Hence, studies on elucidating the molecular events in MSC senescence are important for understanding and subsequently designing curative effects of MSC in clinical applications.

Oxidative stress is thought to contribute significantly to DNA damage and cellular senescence [14-18]. In senescent fibroblasts and other somatic cells, reactive oxygen species (ROS) is produced due to defective mitochondrial functions $[7,19]$, a role supported by premature senescence when cells are treated with oxidants or cultured under hypoxia conditions $[20,21]$. On the other hand, ROS involvement in MSC proliferation remains unclear despite reports that antioxidants, or hypoxic conditions, exert positive effects on the growth rate and replicative lifespan of bone marrow- and adipose-derived MSC [22-26]. In molecular terms, oxidative stress has been shown to activate the tumor suppressors p53 and pRB, leading to induction of premature senescence [22,27-29]. Interactions between accumulation of oxidative DNA damages and the repair processes, and the mechanisms and contribution of mitochondrial dysfunctions to senescence are a few of the outstanding issues that remain to be elucidated.

Understanding oxidative stress in MSC would contribute to design of experimental approaches to delay, prevent or revert oxidative stress-induced replicative senescence in MSC cultures. However, there have not been appropriate study models that avoid extended cell culturing to reach senescence, study models that closely resemble the onset of replicative senescence in long-term culture. Such models are necessary for subsequent studies on the mechanisms of oxidative-stress induced premature senescence (OSIPS). In this work, we aimed to establish an OSIPS model to enable anti-senescence modeling and for subsequent use for developing anti-senescence strategies.

\section{Materials and Methods}

\section{hMSC cell cultures}

Early-passage human mesenchymal stem cell (MSC) lines derived from bone marrow and Wharton's Jelly were obtained from Cryocord Sdn. Bhd, Selangor, Malaysia (http://www.cryocord.com.my). The MSC cell lines were isolated and characterized at Cryocord according to standard procedures and with ethical clearance. Both bone marrow-derived MSC (BM-MSC) and Wharton's Jelly-derived MSC (WJ-MSC) were cultured in complete cell culture medium DMEM-F12 (Gibco, USA), supplemented with $10 \%$ fetal bovine serum (Gibco) and 1\% penicillin/streptomycin (Gibco), at standard culture conditions of $37{ }^{\circ} \mathrm{C}$ with $5 \%$ carbon dioxide. Medium was changed twice a week and at $80 \%$, confluency cells were re-plated at a density of 5,000 cells $/ \mathrm{cm}^{2}$. Cell counting was carried out using a Neubauer counting chamber. Cumulative Population Doubling (CPD) was calculated with the formula $\mathrm{PD}=\log _{2}(\mathrm{hi} / \mathrm{si})$, $\mathrm{CPD}=$ sum, $\mathrm{I}=1 \ldots . \mathrm{nPDPi}$ where hi $=$ obtained number of cells, $s i=$ initial number of cells and $n=$ total number of passage [30].

\section{Hydrogen peroxide $\left(\mathrm{H}_{2} \mathrm{O}_{2}\right)$ treatment}

$\mathrm{H}_{2} \mathrm{O}_{2}$ treatments were performed on confluent cells ( $3.75 \times 10^{5}$ cells per T75 flask) to avoid variability of $\mathrm{H}_{2} \mathrm{O}_{2}$ toxicity. Cells at passage 6-8 were incubated for $2 \mathrm{~h}$ in complete cell culture medium containing $\mathrm{H}_{2} \mathrm{O}_{2}$. Upon $80 \%$ confluence, control MSC cells were re-seeded at a density of $3.75 \times 10^{5}$ cells per T75 flask while the $\mathrm{H}_{2} \mathrm{O}_{2}$-treated cells were split at $1.5 \times 10^{5}$ cells per T75 flask in fresh medium. All flasks used were Nunc ${ }^{\mathrm{TM}}$ Cell Culture Treated Flasks.

\section{$\boldsymbol{\beta}$-galactosidase (SA- $\beta$-Gal) assay}

The positive blue staining of $\beta$-galactosidase was used as a biomarker of cellular senescence. For assessment of SA- $\beta$-gal activity, the cells were fixed with $3 \%$ paraformaldehyde for $30 \mathrm{~min}$, washed with PBS, and stained with a SA- $\beta$-gal detecting kit (Cell Biolabs Inc., USA) according to the manufacturer's instruction and examined under a phase contrast microscope. Expression of senescence-associated SA- $\beta$-gal activity which is present only in senescent cells and is not found in pre-senescent, quiescent, or immortal cells is detectable at pH 6.0 in senescent cells. Staining was done overnight at $37{ }^{\circ} \mathrm{C}$. To avoid staining due to cell confluence rather than to proliferative senescence, the 
assay was performed in sub-confluent cultures displaying comparable cell density.

\section{Real-time RT-PCR}

Total RNA was isolated from hMSC using RNeasy Plus Mini Kit (Qiagen, USA). One microgram of RNA was used for cDNA synthesis using the Phusion RT-PCR kit (Thermo Scientific, EU) according to the manufacturer's instructions. Ten times diluted cDNA was used for quantitative RT-PCR using a SYBR select master mix kit (Applied Biosystems, USA) in an Rotor-Gene $Q$ (Qiagen) thermal cycler and the final volume of PCR reaction was $20 \mu \mathrm{l}$. The following primers were used for qPCR analysis: GAPDH, forward: 5'-AGCCACATCGCTCAGACACC-3' and reverse: 5'-GTACTCAGCGGCCAGCATCG-3'; p53, forward: 5'-TTGAGACTGGGTCTCGCTTT-3' and reverse: 5'-AAATGCAGATGTGCTTGCAG-3'; p21, forward: 5'-GCCTGGACTGTTTTCTCTCG-3' and reverse: 5'-ATTCAGCATTGTGGGAGGAG-3'; p16,

A

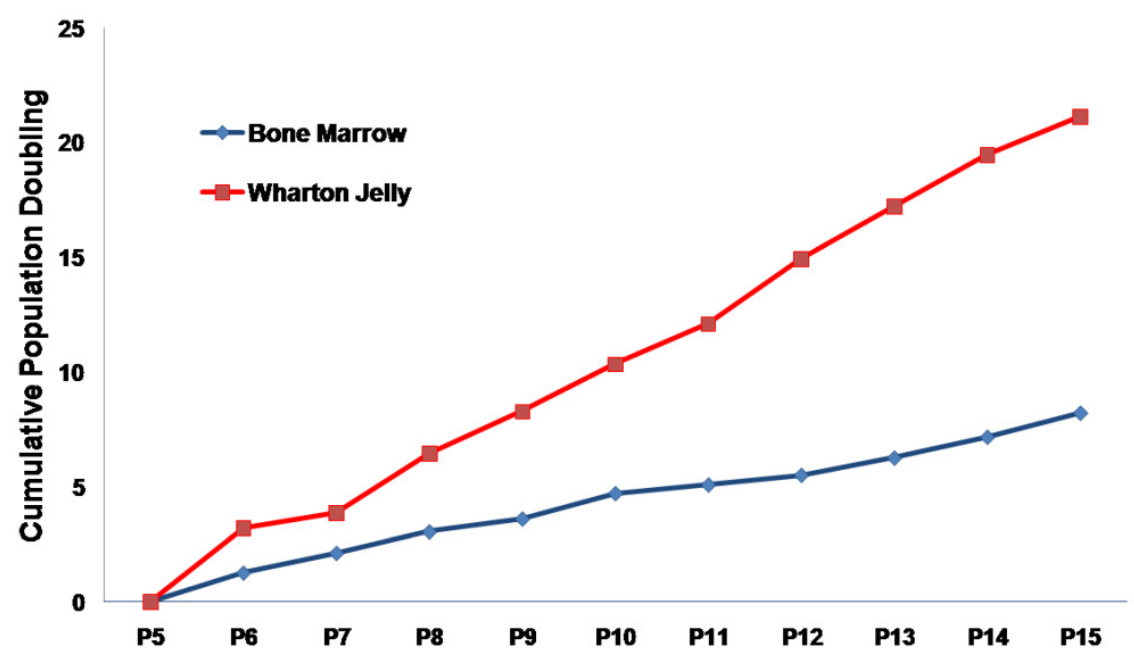

B

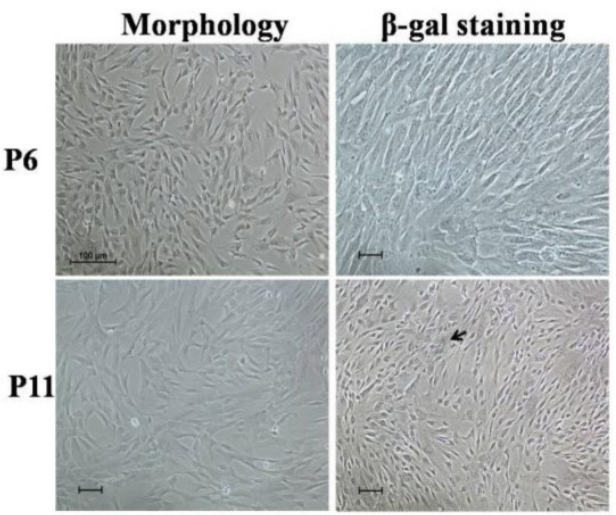

Wharton Jelly (WJ)-derived MSC

Figure I. Comparison of Wharton jelly-derived MSC (WJ-MSC) and bone marrow-derived (BM)-MSC. (a) Cumulative population doubling of WJ- and BM-MSCs. Senescence observed on (b) WJ-MSC and (c) BM-MSC from passage 5 or 6 cultured to PII (black arrows) after morphology examination and SA- $\beta$-gal staining. Scale bar: $100 \mu \mathrm{m}$. forward: 5'-CACGGGTCGGGTGAGAGT-3' and reverse: 5'-CCCAACGCACCGAATAGTTAC-3'; lysosomal $\quad \beta$-galactosidase (GLB1), forward: 5'-CCTACATCTGTGCAGAGTGG-3' and reverse: 5'-TTCATCTTGGGCAGAAGGAC-3'. PCR was carried out with the following conditions: $50{ }^{\circ} \mathrm{C}$ for 2 min, $95^{\circ} \mathrm{C}$ for $2 \mathrm{~min}$ followed by 40 cycles of $95^{\circ} \mathrm{C}$ for $15 \mathrm{~s}$ and $60{ }^{\circ} \mathrm{C}$ for $1 \mathrm{~min}$. The melting curves for a number of PCR products are single-peaked. Data was analyzed by using the comparative $\Delta \Delta \mathrm{Ct}$ method, and the mRNA expressions of p16, p21, p53 and GLB1 were normalized to the GAPDH expression. Reactions were performed in triplicate. Data were analyzed by Student's $t$ test. $P<0.05$ is considered statistically significant.

\section{Results}

Wharton's Jelly (WJ) and bone marrow (BM)-derived mesenchymal stem cells (MSC) are two MSC sources that are frequently used in the development of cell therapy protocols. Prior to attempts in generating OSIPS cells using $\mathrm{H}_{2} \mathrm{O}_{2}$, the growth characteristics of WJ-MSC and BM-MSC were first compared in extended culture (Fig. 1). It was found that the growth of WJ-MSC was more robust and had a growth rate approximately twice that of BM-MSC (Fig. 1A). When cultured from passage 6 to 11, the morphology of WJ-MSC remained unchanged, and there was little SA- $\beta$-gal staining (Fig. 1B), indicating that WJ-MSC had not gone into senescence. The results are consistent with previous reports that WJ-MSC requires a greater number of passages in culture to enter senescence, and can retain stemness properties for a longer period time in vitro [31-33]. On the other hand, culturing BM-MSC from passage 5 to 11 resulted in the cells displaying senescence characteristics in being enlarged and flat in 
shape (Fig. 1C, left panels). Retarded growth rates were also reflected in the passage $11 \mathrm{BM}-\mathrm{MSC}$ culture which stained positively for SA- $\beta$-gal (Fig. 1 C, right panels) further indicating senescence. Our results are in agreement with the study reported by Cheng et al. in which senescence for BM-MSC was observed as early as the 7th or 8th passage [10]. The cells became retarded in proliferation rates, and were enlarged with irregular shape after long-term culture in vitro. Based on the growth characterisation described above, WJ-MSC was chosen for subsequent $\mathrm{H}_{2} \mathrm{O}_{2}$ treatment.

To determine the optimal concentration of $\mathrm{H}_{2} \mathrm{O}_{2}$ in inducing senescence, WJ-MSC was cultured in a medium containing various concentrations of $\mathrm{H}_{2} \mathrm{O}_{2}$. The growth rate of the cells was clearly retarded when cultured in the presence of $200 \mu \mathrm{M} \mathrm{H}_{2} \mathrm{O}_{2}$ (Fig. 2A). The cells were able to undergo 3-4 passages post-treatment prior to complete growth arrest. In contrast, the growth of WJ-MSC was found to be arrested on treatment with 400 and $600 \mu \mathrm{M} \mathrm{H}_{2} \mathrm{O}_{2}$, and the cells were not viable on replating. Cells treated with $200 \mu \mathrm{M} \mathrm{H}_{2} \mathrm{O}_{2}$ resembled the replicative senescence growth retardation of late-passage senescence cells (data not shown). This concentration was reproducibly applied to four different independent

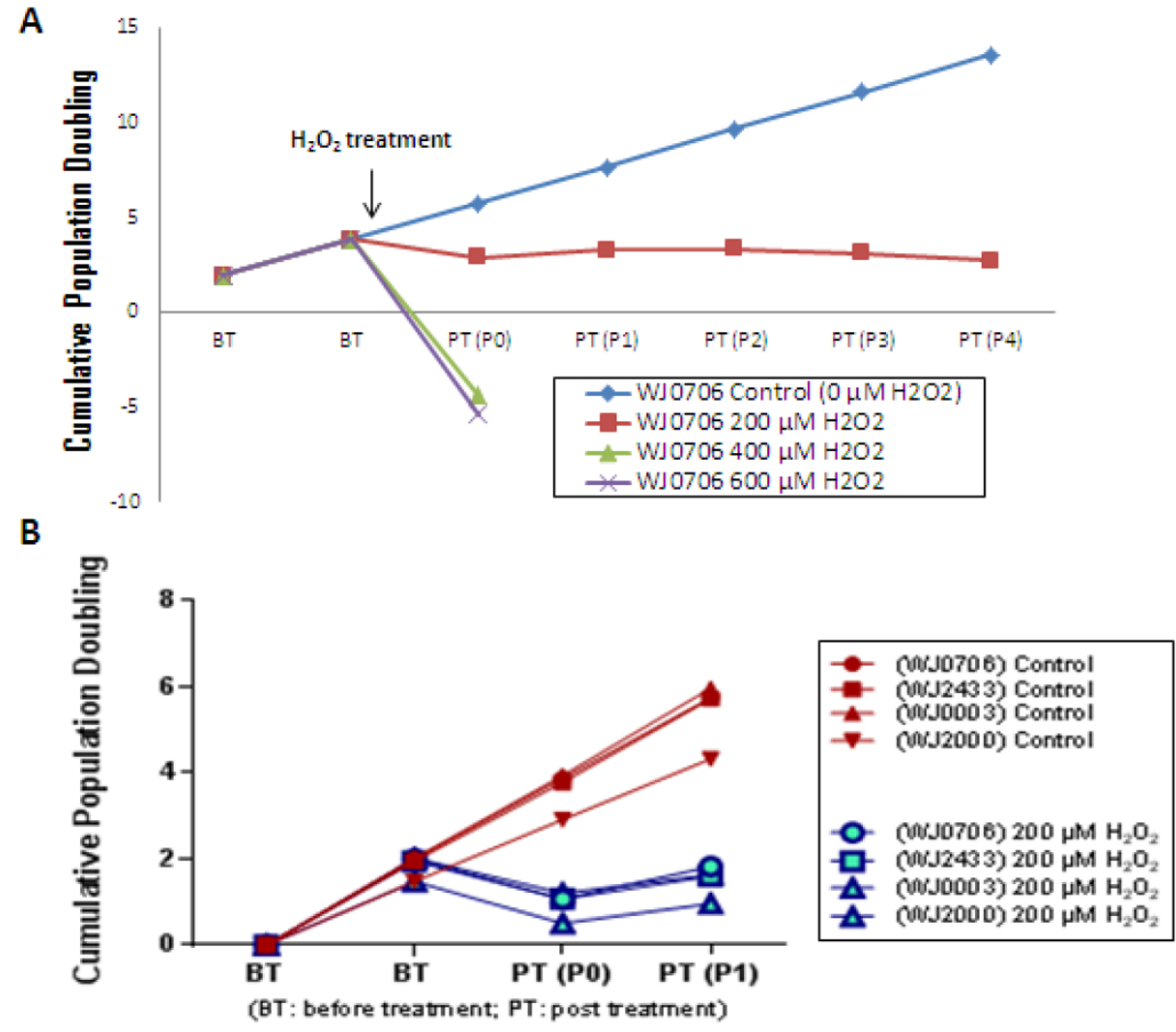

Figure 2. The cell growth profile after treated with different concentration of $\mathbf{H}_{2} \mathbf{O}_{2}$. (a) WJ-MSC sample WJ0706 was treated with different concentrations of $\mathrm{H}_{2} \mathrm{O}_{2}$ followed by determination of cumulative population doubling to determine the relative growth rates of the cells. (b) The optimal $\mathrm{H}_{2} \mathrm{O}_{2}$ concentration was applied to four independent sources of WJ-MSC.
WJ-MSC sources (Fig. 2B) and was used in subsequent experiments. Different types of cells respond differently to $\mathrm{H}_{2} \mathrm{O}_{2}$-induced oxidative stress. Kim et al. [34] reported that low concentrations of $<10 \mu \mathrm{M} \mathrm{H} \mathrm{H}_{2} \mathrm{O}_{2}$ stimulated cell proliferation in fibroblasts, whereas intermediate concentrations of $\sim 150 \mu \mathrm{M}$ resulted in growth arrest and caused senescence, and $>400 \mu \mathrm{M}$ high concentrations of $\mathrm{H}_{2} \mathrm{O}_{2}$ promoted apoptotic cell death. Similar cellular effects of $\mathrm{H}_{2} \mathrm{O}_{2}$ have also been reported in vascular smooth muscle cells [35].

We further examined the morphological changes of $200 \mu \mathrm{M} \mathrm{H} \quad \mathrm{H}_{2} \mathrm{O}_{2}$-treated WJ-MSC. On day 3 post-treatment prior to passaging, and on day 7 after the first passage, the cells became irregular, large and flatten in shape, multinucleated and were heavily granulated (Fig. 3A). These morphological alterations are consistent with reported morphological changes for senescent cells. The cells were positively and strongly stained with SA- $\beta$-gal when first passaged on day 7 , or passaged for the third time on day 27 after treatment, indicating the occurrence of senescence in $\mathrm{H}_{2} \mathrm{O}_{2}$-treated cells (Fig. 3B). To further validate senescence, real-time RT-PCR analysis of expression of the senescence-related gene markers, namely p53, p21, p16 and GLB1, was performed in three different $\mathrm{H}_{2} \mathrm{O}_{2}$-treated WJ-MSC lines (Fig. 4). Relative to the respective untreated parental cells, the four markers were generally upregulated, albeit to various extents, with the possible exception of p53. Furthermore, different WJ cell lines appeared to display different expression profiling patterns. The p53 gene was apparently downregulated in $\mathrm{H}_{2} \mathrm{O}_{2}$-treated WJ2000 cells; p53 levels in the other two WJ cell lines were also only slightly upregulated. p16 and p53 were clearly up-regulated by 2-fold or more in WJ0706 and WJ2000, but the p16 level did not seem to be much affected in WJ2433. Similarly, the $\beta$-galactosidase GLB1 gene levels were also up-regulated to different levels in different WJ lines. Taken together, generally upregulation of senescence-related markers supports $\mathrm{H}_{2} \mathrm{O}_{2}$-induced senescence in $\mathrm{WJ}$ cells. 
$\mathbf{A}$

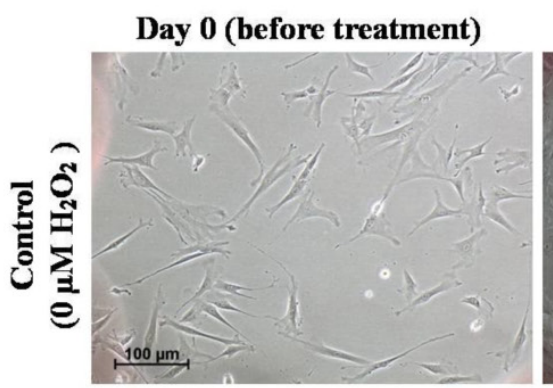

Day 3 (P0 post treatment)

Day 7 (P1 post treatment)

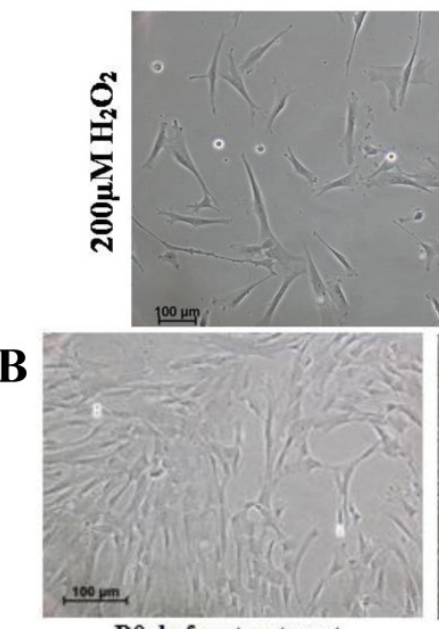

D0, before treatment
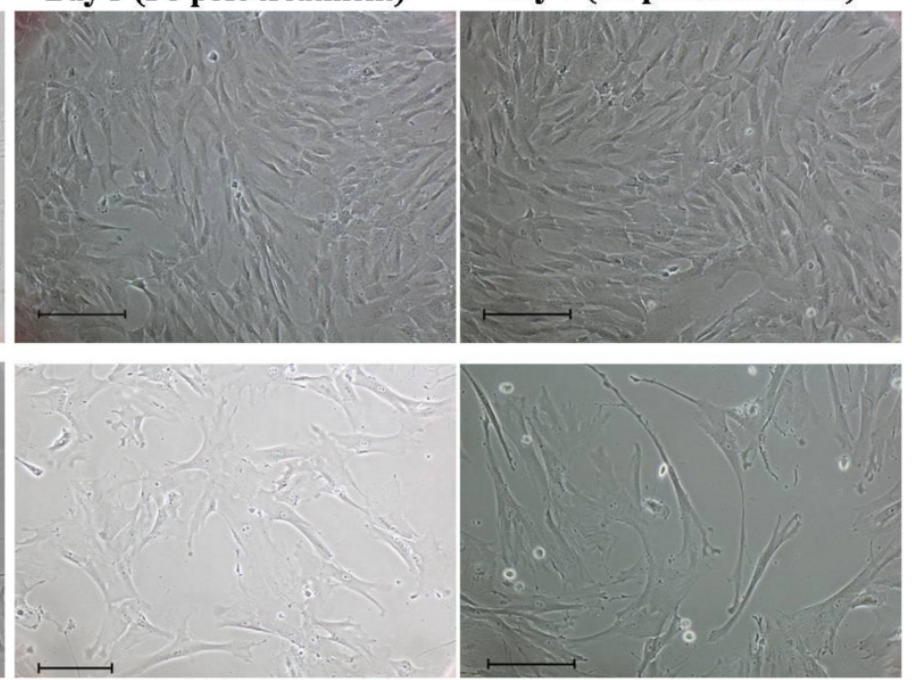

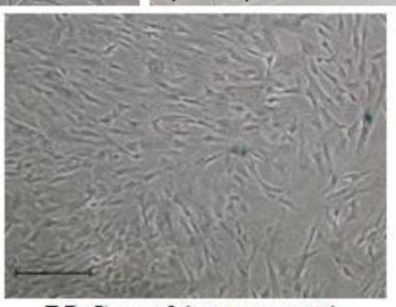

D7, Control (no treatment) P3 post treatment

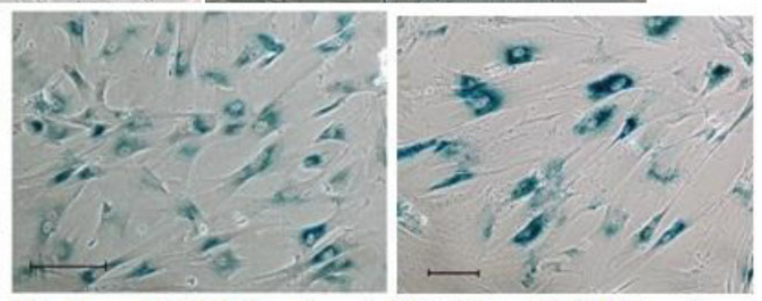

D7, P1 post $200 \mu \mathrm{M}$ treatment $\mathrm{D27}, \mathrm{P3}$ post $200 \mu \mathrm{M}$ treatment

Figure 3. Characteristics of senescence in $\mathbf{H}_{2} \mathrm{O}_{2}$-treated WJ-MSC. (a) Morphological changes of $\mathrm{H}_{2} \mathrm{O}_{2}$-treated cells on days 3 post-treatment prior to passaging, and on day 7 after first passage. (b) $\mathrm{H}_{2} \mathrm{O}_{2}$-treated cells stained positively for SA- $\beta$-gal. Scale bar: $100 \mu \mathrm{m}$.

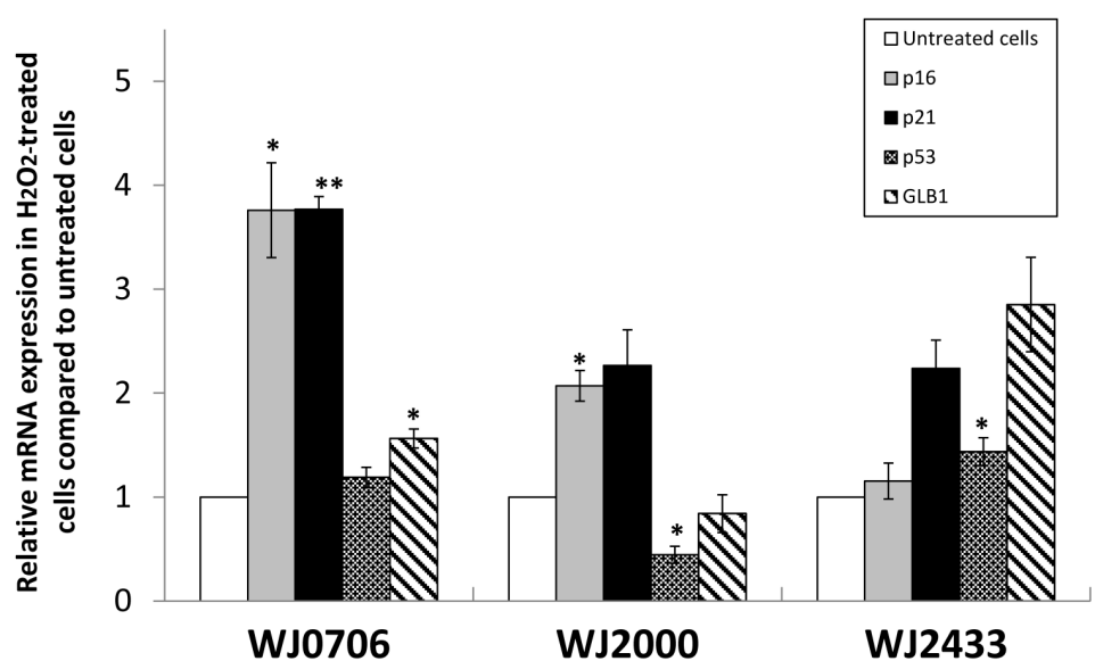

Figure 4. The expression of senescence markers in $\mathrm{H}_{2} \mathrm{O}_{2}$-treated WJ-MSC cell lines WJ2433, WJ0706 and WJ2000. An elevated expression of $\mathrm{p} 53$, p2I, pl6, and lysosomal $\beta$-galactosidase (GLBI) was detected in $\mathrm{H}_{2} \mathrm{O}_{2}$-treated WJ-MSC cell lines, except for $\mathrm{p} 53$ and GLBI expression in WJ2000, using real-time RT-PCR, All experiments were performed triplicates. Data are means \pm S.E.M. $(* P<0.05, * * P<0.01)$.

\section{Discussion}

The present work demonstrated the possibility of using subcytotoxic concentration of $\mathrm{H}_{2} \mathrm{O}_{2}$ to induce senescence-like features in Wharton's Jelly derived MSC, a study model which is feasible and useful for future applications in investigation on molecular events regulating OSIPS, and in applications for screening anti-oxidants that retard, prevent or reverse OSIPS. Human umbilical cord blood-derived MSC is high sensitive to oxidative stress compared with other MSC types due to reduced activities of antioxidant enzymes; however, exogenous addition of anti-oxidants, such as PEG-catalase, is able to restore cell resistance of stress [5].

Numerous examples have been reported on the 
regenerative applications of BM-MSCs, including repair of cardiovascular muscles, bone and cartilage as well as in treatment of lung fibrosis and coronary artery disease [36-38]. In this work, we show that another neonatal source of MSC, MSC derived from the Wharton's Jelly of the umbilical cord, tolerated $\mathrm{H}_{2} \mathrm{O}_{2}$-induced oxidative stress up to $200 \mu \mathrm{M}$ concentration. For use of lower and subcytotoxic $\mathrm{H}_{2} \mathrm{O}_{2}$ concentrations, prolonged treatment may be necessary to induce senescence-like features $[39,40]$. On the other hand, high concentrations of $\mathrm{H}_{2} \mathrm{O}_{2}$ inflect damages to biological macromolecules and delay degeneration and detoxification by cellular enzymes, leading to lethal oxidative damages and eventual cell death $[41,42]$.

Clinical applications of WJ-MSC have only recently been ardently reported [43-45]. Understanding OSIPS in WJ-MSC is a prelude to developing protective measures against stress-induced premature senescence. Resveratrol is one of more successful drugs shown to exert such protective effects under various laboratory conditions in cell and animal models [46-48]. It remains to be investigated if resveratrol exert similar desirable effects on WJ-MSC.

\section{Conclusions}

Established OSIPS model of WJ-MSC displays the growth characteristics of near-replicative senescence for up to 3 passages before entering senescence. This near-replicative senescence 'window' of several passages makes the OSIPS model a possible platform to investigate molecular mechanisms of senescence and to screen potential anti-oxidative agents to delay, curb or revert oxidative stress-promoted replicative senescence.

\section{Abbreviations}

MSCs: mesenchymal stem cells; OSIPS: oxidative stress-induced pre-mature senescence; $\mathrm{H}_{2} \mathrm{O}_{2}$ : hydrogen peroxide; hMSC: human MSC; BM-MSC: bone marrow-derived hMSC; WJ-MSC: Wharton's Jelly-derived hMSC; CPD: cumulative population doubling; SA- $\beta$-gal: senescence-associated $\beta$-galactosidase; P: passage; GLB1: lysosomal $\beta$-galactosidase.

\section{Acknowledgements}

This work was supported by HIR-MoE Grant (Reference number -UM.C/625/1/HIR/MOHE/ CHAN/03, account number - A000003-50001).

\section{Competing Interests}

The authors have declared that of no existing competing interests.

\section{References}

1. Williams AR, Hare JM. Mesenchymal stem cells: biology, pathophysiology, translational findings, and therapeutic implications for cardiac disease. Circ Res. 2011; 109:923-40.

2. Brandl A, Meyer M, Bechmann V, et al. Oxidative stress induces senescence in human mesenchymal stem cells. Exp Cell Res. 2011; 317:1541-7.

3. Roobrouck VD, Ulloa-Montoya F, Verfaillie CM. Self-renewal and differentiation capacity of young and aged stem cells. Exp Cell Res. 2008; 314:1937-44

4. Wagner W, Horn P, Castoldi M, et al. Replicative senescence of mesenchymal stem cells: a continuous and organized process. PLoS One. 2008; 3:e2213.

5. Ko E, Lee KY, Hwang DS. Human umbilical cord blood-derived mesenchymal stem cells undergo cellular senescence in response to oxidative stress. Stem Cell Dev. 2012; 21:1877-86.

6. Saretzki G. Cellular senescence in the development and treatment of cancer. Curr Pharm Design. 2010; 16: 79-100.

7. Passos J, Saretzki G, Ahmed S, et al. Mitochondrial dysfunction accounts for the stochastic heterogeneity in telomere-dependent senescence. PLoS Biol. 2007; 5:e110.

8. Alt EU, Senst C, Murthy SN, et al. Aging alters tissue resident mesenchymal stem cell properties. Stem Cell Res. 2012; 8:215-25.

9. Wagner $\mathrm{W}$, Bork $\mathrm{S}$, Horn $\mathrm{P}$, et al. Aging and replicative senescence have related effects on human stem and progenitor cells. PLoS One. 2009; 4:e5846.

10. Cheng HC, Qiu L, Ma J, et al. Replicative senescence of human bone marrow and umbilical cord derived mesenchymal stem cells and their differentiation to adipocytes and osteoblasts. Mol Biol Rep. 2011; 38:5161-8.

11. Vigneron A, Vousden KH. p53, ROS and senescence in the control of aging. Aging. 2010; 2: 471-4.

12. Shibata KR, Aoyama T, Shima $\mathrm{Y}$, et al. Expression of the p16INK4A gene is associated closely with senescence of human mesenchymal stem cells and is potentially silenced by DNA methylation during in vitro expansion. Stem Cells. 2007; 25:2371-82

13. JinY, Kato T, Furu M, et al. Mesenchymal stem cells cultured under hypoxia escape from senescence via down-regulation of p16 and extracellular signal regulated kinase. Biochem Biophys Res Commun. 2010;391:1471-6.

14. Haines DD, Juhasz B, Tosaki A. Management of multicellular senescence and oxidative stress. J Cell Mol Med. 2013; 17:936-57.

15. Chen JH, Stoebar K, Kingsbury S, et al. Loss of proliferative capacity and induction of senescence in oxidatively stressed human fibroblasts. J Biol Chem. 2004; 279:49439-46.

16. von Zglinicki T. Oxidative stress shortens telomeres. Trends Biochem Sci. 2002; 27:339-44.

17. Passos JF, von Zglinicki T, Saretzki G. Mitochondrial dysfunction and cell senescence: cause or consequence? Rejuvenation Res. 2006; 9:64-8.

18. Passos JF, von Zglinicki T. Oxygen free radicals in cell senescence: are they signal transducers? Free Radic Res. 2006; 40:1277-83.

19. Allen RG, Tresini M, Keogh BP, Doggett DL, Cristofalo VJ. Differences in electron transport potential, antioxidant defenses, and oxidant generation in young and senescent fetal lung fibroblasts (WI-38). J Cell Physiol. 1999; 180:114-22.

20. von Zglinicki T, Saretzki G, Docke W, Lotze C. Mild hyperoxia shortens telomeres and inhibits proliferation of fibroblasts: a model for senescence? Exp Cell Res. 1995; 220:186-93.

21. Chen QM, Prowse KR, Tu VC, Purdom S, Linskens MH. Uncoupling the senescent phenotype from telomere shortening in hydrogen peroxide-treated fibroblasts. Exp Cell Res. 2001; 265:294-303.

22. Tsai CC, Chen YJ, Yew TL, et al. Hypoxia inhibits senescence and maintains mesenchymal stem cell properties through down-regulation of E2A-p21 by HIF-TWIST. Blood. 2011; 117:459-69.

23. Lin TM, Tsai JL, Lin SD, Lai CS, Chang CC. Accelerated growth and prolonged lifespan of adipose tissue-derived human mesenchymal stem cells in a medium using reduced calcium and antioxidants. Stem Cells Dev. 2005; 14:92-102.

24. Choi KM, Seo YK, Yoon $\mathrm{HH}$, et al. Effect of ascorbic acid on bone marrow-derived mesenchymal stem cell proliferation and differentiation. J Biosci Bioeng. 2008; 105:586-94.

25. Wang $\mathrm{KH}$, Kao $\mathrm{AP}$, Wangchen $\mathrm{H}$, et al. Optimizing proliferation and characterization of multipotent stem cells from porcine adipose tissue. Biotechnol Appl Biochem. 2008; 51:159-66.

26. Li H, Chen JW, Zhu LL, Jin B, Huang X, Fan M. Continuous hypoxia improves the proliferation of human bone marrow-derived mesenchymal stem cells in vitro. Basic Med Sci Clin. 2005; 25:268-71.

27. Liu D, Xu Y. p53, oxidative stress, and aging. Antioxid Redox Signal. 2011; 15:1669-78.

28. Toussaint O, Weemaels G, Debacq-Chainiaux F, et al. Artefactual effects of oxygen on cell culture models of cellular senescence and stem cell biology. J Cell Physiol. 2011; 226:315-21.

29. Estrada JC, Torres Y, Benguria A, et al. Human mesenchymal stem cell-replicative senescence and oxidative stress are closely linked to aneuploidy. Cell Death Dis. 2013; 4:e691.

30. Schellenberg A, Lin Q, Schüler H, et al. Replicative senescence of mesenchymal stem cells causes DNA-methylation changes which correlate with repressive histone marks. Aging (Albany NY). 2011; 3:873-88. 
31. Troyer DL, Weiss ML. Weiss, Wharton's jelly-derived cells are a primitive stromal cell population. Stem Cells. 2008; 26:591-9.

32. Nekanti U, Dastidar S, Venugopal P, et al. Increased proliferation and analysis of differential gene expression in human Wharton's jelly-derived mesenchymal stromal cells under hypoxia. Int J Biol Sci. 2010; 6:499-512.

33. Ruan D, Zhang Y, Wang DL, et al. Differentiation of human Wharton's jelly cells toward nucleus pulposus-like cells after coculture with nucleus pulposus cells in vitro. Tissue Eng Part A. 2012; 18:167-75.

34. Kim BY, Han MJ, Chung AS. Effects of reactive oxygen species on proliferation of Chinese hamster lung fibroblast (V79) cells. Free Radic Biol Med. 2001; 30:686-98.

35. Taniyama Y, Griendling KK. Reactive oxygen species in the vasculature: molecular and cellular mechanisms. Hypertension. 2003; 42:1075-81.

36. Wakitani S, Imoto K, Yamamoto T, et al. Human autologous culture expanded bone marrow mesenchymal cell transplantation for repair of cartilage defects in osteoarthritic knees. Osteoarthritis Cartilage. 2002; 10:199-206.

37. Barry FP, Murphy JM. Mesenchymal stem cells: clinical applications and biological characterization. Int J Biochem Cell Biol. 2004; 36:568-84.

38. Orlic D, Kajstura J, Chimenti S, et al. Bone marrow cells regenerate infarcted myocardium. Nature. 2001; 410: 701-5.

39. Frippiat C, Chen QM, Zdanov S, Magalhaes JP, Remacle J, Toussaint O. Subcytotoxic $\mathrm{H} 2 \mathrm{O} 2$ stress triggers a release of transforming growth factor-beta 1, which induces biomarkers of cellular senescence of human diploid fibroblasts. J Biol Chem. 2001. 276:2531-7.

40. Frippiat C, Dewelle J, Remacle J, Toussaint O. Signal transduction in $\mathrm{H} 2 \mathrm{O} 2$-induced senescence-like phenotype in human diploid fibroblasts. Free Radic Biol Med. 2002; 33:1334-46.

41. Balaban RS, Nemoto S, Finkel T. Mitochondria, oxidants, and aging. Cell. 2005; 120:483-95.

42. Buettner GR. Superoxide dismutase in redox biology: the roles of superoxide and hydrogen peroxide. Anticancer Agents Med Chem. 2011; 11:341-6.

43. Peng J, Wang Y, Zhang L, et al. Human umbilical cord Wharton's jelly-derived mesenchymal stem cells differentiate into a Schwann-cell phenotype and promote neurite outgrowth in vitro. Brain Res Bull. 2011; 84:235-43.

44. Sabapathy V, Sundaram B, Vm S, Mankuzhy P, Kumar S. Human Wharton's jelly mesenchymal stem cells plasticity augments scar-free skin wound healing with hair growth. PLoS One. 2014; 9:e93726.

45. Batsali AK, Kastrinaki MC, Papadaki HA, Pontikoglou C. Mesenchymal stem cells derived from Wharton's Jelly of the umbilical cord: biological properties and emerging clinical applications. Curr Stem Cell Res Ther. 2013; 8:144-55.

46. Fukui M, Choi HJ, Zhu BT. Mechanism for the protective effect of resveratrol against oxidative stress-induced neuronal death. Free Radic Biol Med. 2010; 49:800-13

47. Movahed A, Yu L, Thandapilly SJ, Louis XL, Netticadan T. Resveratrol protects adult cardiomyocytes against oxidative stress mediated cell injury. Arch Biochem Biophys. 2012; 527:74-80.

48. Juhasz B, Varga B, Gesztelyi R, Kemeny-Beke A, Zsuga J, Tosaki A. Resveratrol: a multifunctional cytoprotective molecule. Curr Pharm Biotechnol. 2010; 11:810-8. 